\title{
Incomplete revascularization of coronary artery in cardiac arrest survivors is associated increased mortality and
}

unfavorable neurological outcome

Chih-Wei Sung, MD ${ }^{1}$; Meng-Che Wu, MD ${ }^{1}$; Joyce Tay, MD² ; Chien-Hua Huang, MD, PhD² * Wen-Jone Chen, MD, PhD ${ }^{2}$; Wei-Tien Chang, MD, PhD ${ }^{2}$; Min-Shan Tsai, MD, PhD ${ }^{1,2}$

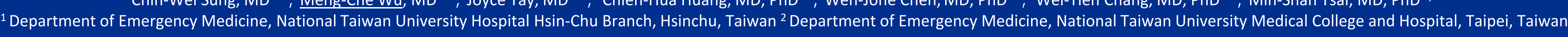

\section{PURPOSE}

To investigate the association between incomplete revascularization of coronary artery stenosis with sury neurological outcomes in cardiogenic arrest survivors

\section{METHODS}

This multi-center, retrospective cohort study recruited 273 adult patients who were successfully resuscitated from nontraumatic cardiac arrest and received emergent coronary angiography (CAG) from 2011 to 2017. The individual coronary artery was defined as severe stenosis when stenosis was more than $\mathbf{7 0} \%$. Incomplete revascularization was considered when a residual stenosis of more than $70 \%$ in any of major coronary arteries occurred.

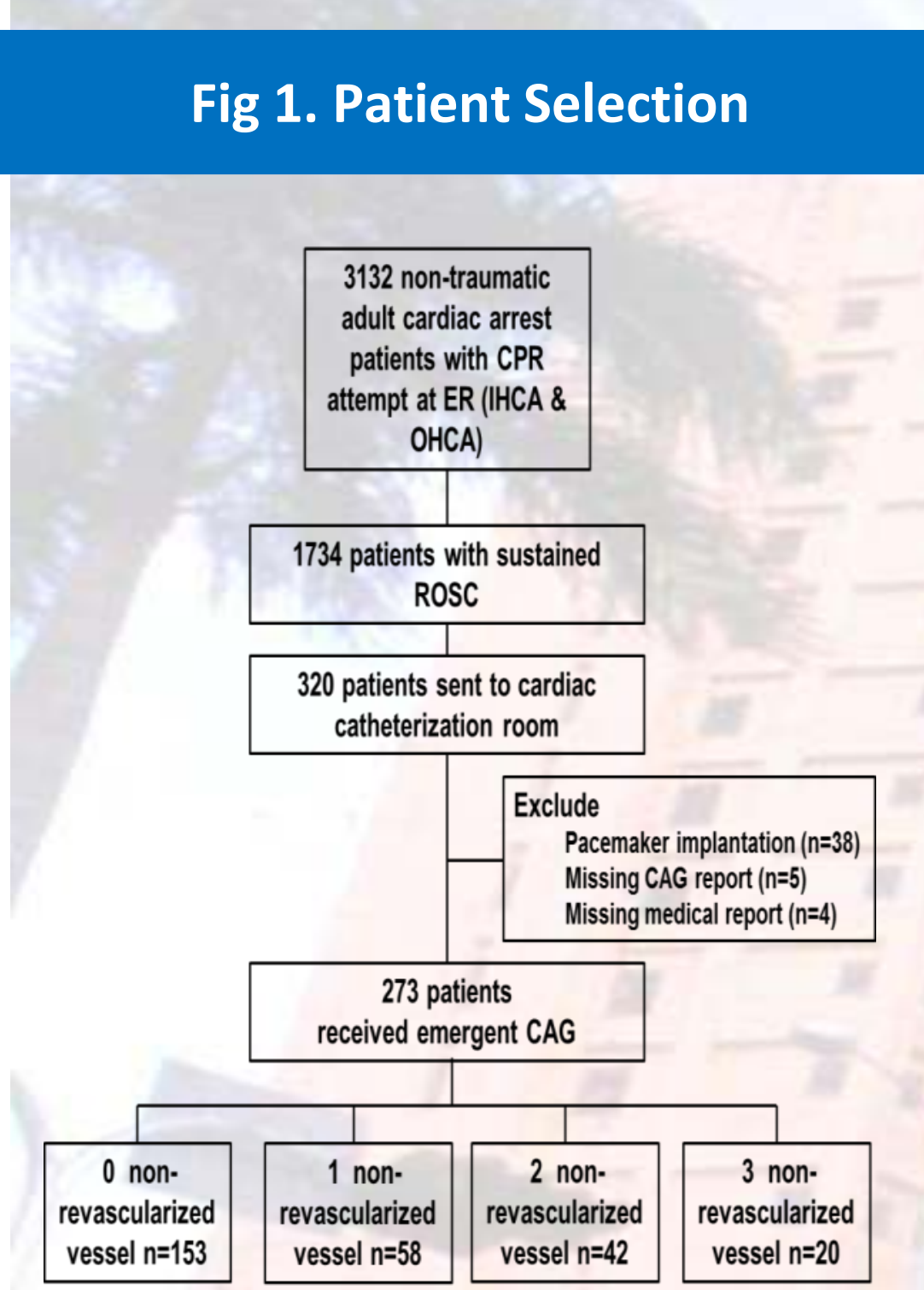

\section{Result}

Among the enrolled patients, there were 120 patients (43.96\%) had incomplete revascularization. Baseline characteristics between different incomplete revascularized coronary artery groups were listed in Table 1. Resuscitation events between different incomplete revascularized coronary artery groups were listed in Table 2. The CPR duration is significant longer with more numbers of non-revascularized coronary artery $(p<0.001)$.

All the 3 groups with non-revascularized vessels were found to have significantly higher incidence of in-hospital mortality when compared with patients without non-revascularized vessel higher (1-vessel: adjusted HR 6.90, 95\% CI 3.36-14.97, $p<0.001 ; 2$-vessel: adjusted HR 13.06, 95\% Cl 3.94-34.18, $p<0.001$; 3-vessel: adjusted HR 15.76, 95\% Cl 4.76-52.14, $p<0.001$ ) (Table 3).

There were 135 patients discharged with unfavorable neurological outcome (CPC=3 5). The increase number of incompletely revascularized vessel was correlated with unfavorable neurological outcome (1-vessel: adjusted HR 3.74, 95\% Cl 1.96-7.17, $p<0.001 ; 2$-vessel: adjusted HR 5.08, 95\% C 2.57-10.27, $p<0.001$; 3-vessel: adjusted HR 6.02, 95\% Cl 1.84-15.13, $p=0.004)$.

\section{CONCLUSIONS}

The increased number of coronary artery with incomplete revascularization in successfully resuscitated patients with cardiogenic arrest was associated with adverse survival and neurological outcomes.

DECLARATION OF INTEREST

The authors declared that they have no conflict of interest, including relevant financial interests, activities, relationships, and affiliations.

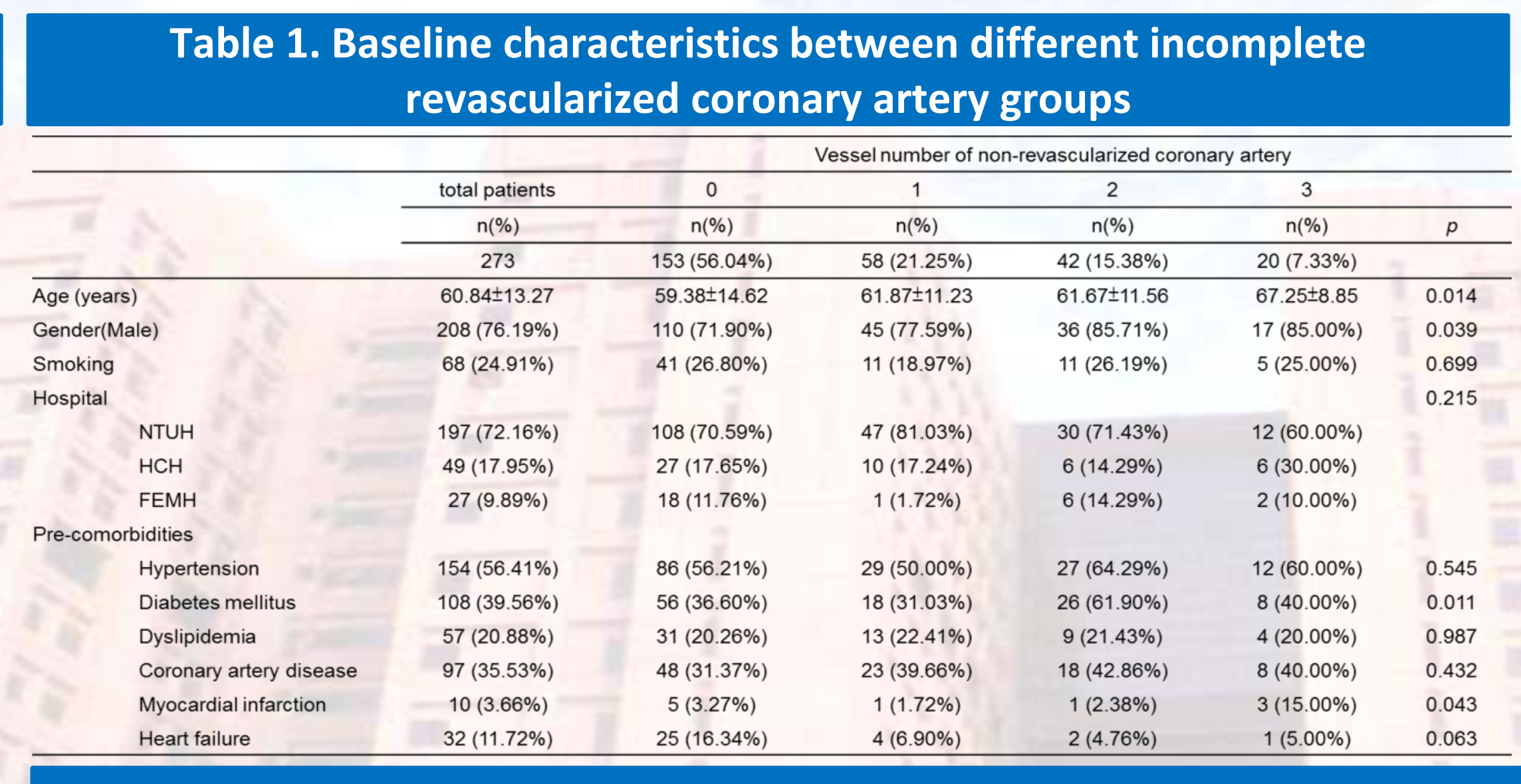

Table 2. Resuscitation events between different un-revascularized groups

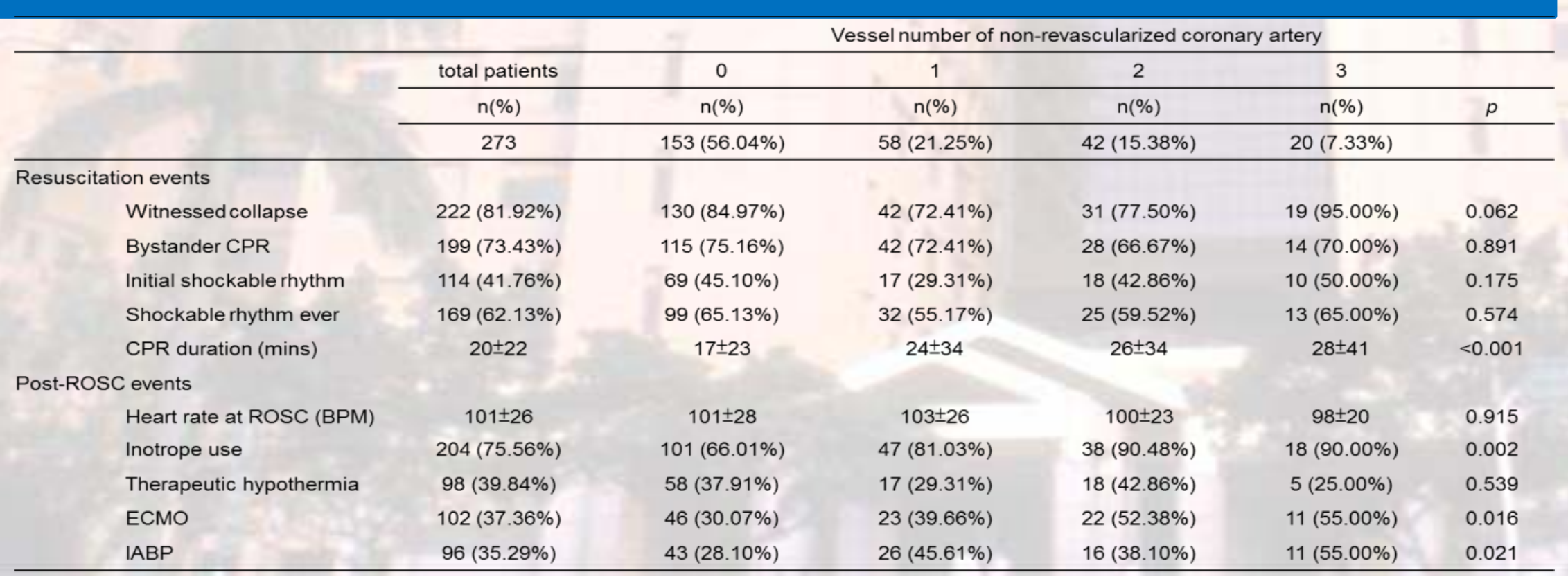

Table 3. The association of stenosis and revascularization of coronary artery with poor neurological outcome Inhospital mortality $\quad$ Unadjusted HR (95\% CI) $\quad p \quad$ Adjusted HR (95\% CI) $\begin{array}{ll} & \\ \text { Vessel number of non-revascularized coronary artery } & \text { Reference }\end{array}$

$\begin{array}{lll}0 & \text { Reference } & \text { Reference }\end{array}$

$\begin{array}{lllll}1 & 32 / 58(55.17 \%) & 6.01(3.08,11.72) & <0.001 & 6.90(3.36,14.97) \\ 2 & 32 / 42(76.19 \%) & 14.63(4.84,35.70) & <0.001 & 13.06(3.94,34.18)\end{array}$

$16.65(4.90,43.87)-<0.001$

Poor neurological $\quad$ Unadjusted HR $(95 \%$ CI) $\quad p \quad$ Adjusted HR $(95 \%$ CI $)$
outcome Unadjusted HR ( $95 \%$ CI)

Adjusted HR (95\% CI) Vessel number of non-revascularized coronary artery 